\title{
What is the solution?
}

SIR - The centenary of Sydney Ringer's important work ${ }^{1}$ on the ionic requirements for maintenance of viability of living tissues in vitro has, astonishingly, been unremarked; it was not even mentioned at the recent 29th International Congress of the International Union of Physiological Sciences in Sydney, Australia. In the same field we are approaching the 75th anniversary of Tyrode's contribution ${ }^{2}$ and have just passed the 50th anniversary of the advance made by Krebs and Henseleit ${ }^{3}$. The use of Ringer's, Tyrode's and Krebs' solutions in biomedical research must be among the most common techniques of science, perhaps even rivalling Student's $t$ test. I estimate that Krebs' solution alone features in more than 10,000 scientific papers a year.

These solutions, and their better nourished relatives, the tissue culture media, represent a veritable scientific Ganges. They have become holy waters, with all of the associated mysticism, dogma, priesthoods and devout acolytes. Nostrums from the ancient scriptures, frequently mistranslated to include idiosyncratic errors, are being perpetuated unquestioningly through generations of disciples. There have even been attempts at minor deification with the eponyms "Ringer" and "Krebs" being applied, respectively, to almost any such solution and to bicarbonate $/ \mathrm{CO}_{2}$ buffered solutions in particular. It has been forgotten that the tissue sustaining properties of normal saline were known before Sydney Ringer and that bicarbonate $/ \mathrm{CO}_{2}$ buffered salines were in use before Krebs and Henseleit.

But none of these solutions was designed to simulate the natural bathing fluid of tissue cells, the milieu interieur of Claude Bernard. All were based on what was known of blood plasma composition and were adjusted empirically to produce a desired response. This has resulted in the use of solutions which maintain grossly abnormal $p \mathrm{H}$, electrical potential and osmotic equilibrium in the isolated tissues they support. Because such phenomena as cellular excitability, drug-receptor interaction and enzyme activity may be profoundly affected, why do these solutions continue to be used?

Certainly, there are occasional glimmers of awareness, as a few authors each year notice some of the unphysiological characteristics of Krebs', Tyrode's and Ringer's solutions. These continual rediscoveries have resulted in a multiplicity of slightly "'modified" solutions. The fact that each of these is capable of maintaining tissues in a reasonably functional state should not be surprising. Living cells have to cope with the fluctuations produced by water intoxication or dehydration, high or low salt intake, labile $p \mathrm{H}$ and such ionic imbalances as result from muscle exercise during marathon running, for example. Nor should it be surprising that some cellular functions are best demonstrated in solutions with defined, even highly abnormal, compositions. But, if our objective is to gain insight into in vivo function, we should expect normal cellular function only in cells coping with environmental conditions close to normal.

Is there a fundamentalist conspiracy promoting a scotomatical attitude among biomedical scientists so that even those who are in the forefront of the giga-ohmlaser-dye-coupled-computerized-tomographic-recombinant-DNA style of cellular research continue to use string and sealing wax technology for their "physiological bathing solutions'"?

I espouse heresy. In 1969, I devised a solution based quantitatively upon the ionic composition of a representative mammalian interstitial fluid ${ }^{4}$. This I termed synthetic interstitial fluid (SIF) and it has been used with great success in many laboratories, notably in experiments on isolated human and other mammalian muscles. SIF may not be the ultimate in physiologically balanced salt solutions but it certainly surpasses those now being used.

\section{A. H. BRETAG}

School of Pharmacy,

South Australian Institute of Technology,

North Terrace,

Adelaide, South Australia 5000

1. Ringer, S. L., J. Physiol, Lond, 4, 222-225 (1883)

2. Tyrode, M.V. Archs int. Pharmacodyn. Ther 20, 205-223 (1910)

3. Krebs, H.A. \& Henseleit, K. Hoppe-Seyler's Z. physiol. Chem. 210, 33-66 (1932)

4. Bretag, A.H. Life Sci. 8, 319-329 (1969).

\section{ITP nomenclature}

S IR - The interesting recent letter Nature (3 November, 1983 p.67-69) and News and Views article (3 November, p.16-17) on the possible second messenger function of inositol 1,4,5-trisphosphate may presage a surge of interest in the function and metabolism of inositol phosphates. It would therefore be helpful immediately to establish acceptable and unambiguous abbreviations of these compounds. Streb $e t$ al. did to a large degree achieve this aim; for example, they used Ins $1,4,5 \mathrm{P}_{3}$ to indicate inositol 1,4,5-trisphosphate. However, they unfortunately chose cyclic IMP as their abbreviation for inositol 1,2-cyclic phosphate: their own logic would demand the abbreviation Ins1,2cyclicP, and cyclic IMP would normally be taken to mean inosine 3, 5-cyclic phosphate.

Hesketh's News and Views item was less careful: the inositol lipids were referred to by the outdated PI and PI-4,4-bisphosphate terminology, rather than as PtdIns and PtdIns4,5P , and Ins 1,4,5P $\mathrm{P}_{3}$ appeared as ITP, which is internationally accepted as an abbreviation for inosine triphosphate. Although the abbreviations in which inositol appears as Ins are more cumbersome, they are unambiguous, and this is a great virtue in a field into which many new workers are moving.

Another flaw in the published material was the incorrect citation of our recent paper (ref. 5 of the News and Views item): the correct citation is Biochem, J. 212, 733-747; 1983).

\section{Department of Biochemistry,}

R. H. MICHELL

University of Birmingham,

PO Box 363, Birmingham B15 2TT, UK

1. Rubenstein, E., Bonner, W.A., Noyes, H.P. \& Brown, G.S. Nature 306, 118 (1983).

2. Landstreet, J.D. \& Angel, J.R.P. Nature 230, 103 (1971).

3. Martin, P.G., llling, R. \& Angel, J.R.P. Mon. Not, R. astr. Soc. 159, 191-201 (1972)

4. Korchak, A.A. \& Syrovatskii, S.I. Astr. Zh. 38, 885-897. (1961); Soviet Astr. -AJ 5, 678-686 (1962).

Legg, M.P.C. \& Westfold, K.C. Astrophys. J. 154, 499-514 (1968)

6. Epstein, R.I. Astrophys. J. 183, 593-610 (1973).

7. Chanmugam, G. \& Dulk, G.A. Astrophys. J. 244, 569-578 (1981).

\section{Familial cancers}

SIR - Several reports have recently appeared showing that familial retinoblastoma is due to mutations in each of the two copies of an autosomal gene. In a review of this work in Nature ${ }^{1}$ your reviewer, like most people writing about the genetics of retinoblastoma, implies that Alfred Knudson was the originator of the idea that certain familial cancers such as retinoblastoma could be due to the combination of an inherited mutation and a somatic mutation. Actually this hypothesis was proposed by Robert de Mars in a symposium organized by the University of Texas M.D. Anderson Hospital ${ }^{2}$, two years before Knudson's first paper on the subject.

Until then, familial retinoblastoma had been classified as due to an autosomal dominant mutation, but de Mars made the following point: “. . . I suggest that many of the pedigrees that are labelled as autosomal dominants . . . could actually be interpreted as autosomal recessives. We must relate the terms dominant and recessive not only to the level of the individual as a whole . . . but also to the level of the individual cell, or cells, which are involved. I think many pedigrees are consistent with the notion that one of the parents in these families might be heterozygous for a recessive and that the neoplasms appear as a result of subsequent somatic mutations in which individual cells become homozygous for a recessive neoplasm-causing gene."

Department of Cancer Biology, Harvard School of Public Health, 665 Huntingdon Avenue,

Boston, Massachusetts 02115, USA

Gilbert, F. Nature 305, 761-762 (1983)

2. de Mars, R. in 23rd an. Symp. Fundamental Cancer Research, 1969, 105-106 (Williams and Wilkins, Baltimore, Maryland, 1970) 